\title{
COMMUNICATION LAYER BETWEEN CONTROL UNITS WITHIN THE INTERNET OF THINGS
}

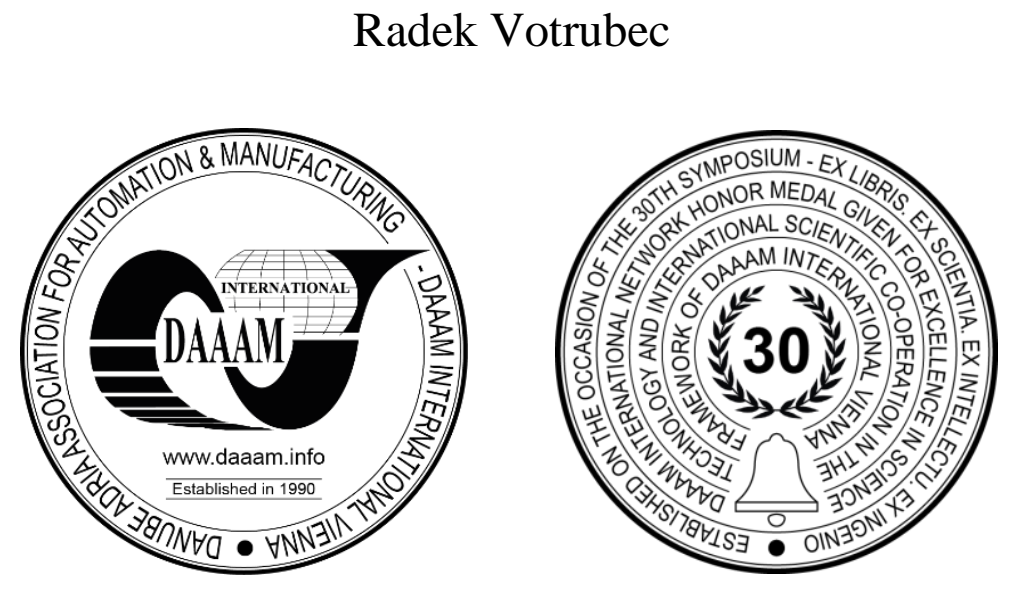

This Publication has to be referred as: Votrubec, R[adek] (2020). Communication Layer between Control Units within the Internet of Things, Proceedings of the 31st DAAAM International Symposium, pp.0072-0079, B. Katalinic (Ed.), Published by DAAAM International, ISBN 978-3-902734-29-7, ISSN 1726-9679, Vienna, Austria DOI: $10.2507 / 31$ st.daaam.proceedings.010

\begin{abstract}
This paper deals with the design of a communication layer between the components of a smart factory or other system. Each member of the Internet of Things has its own control system based on microprocessor. All IoT components have to work with programmable analog and digital inputs and outputs and other buses and have to communicate, exchange information and cooperate with each other. The control units are equipped with wifi modules and it is necessary to design program structures for communication. Control units must be able to solve combination and sequential problems based on automata. Closed graphs of control unit automats are interconnected by means of wifi messages. The structure of these messages is designed, which must contain component addresses and transmitted information of various types, character, string, numeric variables and arrays. A general library of functions containing typical elements of automata was designed. This general library has been implemented on two specific production systems and home automation tasks.
\end{abstract}

Keywords: Smart factory; Arduino; Industry 4.0; Wifi communication; automation.

\section{Introduction}

We created several production systems or models of production system and home automation systems at our department in the last few years. Production systems are suitable for teaching the modern principles of Industry 4.0. [4], [6], [8]. Thanks to similar innovations, manufacturing companies can achieve an increase in product quality, which is the main competitive criterion today [7], [9]. All these systems are not based on central control but each element of the system has its own control system and communicates with the other elements of the system within Internet of Things. The first is a model of a smart factory with the production of a colourful bracelet, where the individual components are a server, a vehicle and several stacks of beads [1].

The second is production system of the little plate with name, which consists of a plate warehouse, a vehicle and a milling machine [2]. Next two models of intelligent houses with enhanced home automation systems were developed [3]. The smart wiring of houses solves lights, heating, ventilation, shading of windows and security alarm. The models of houses can be extended with new control units with additional functions such as additional temperature or humidity sensor, watering flower, control of pool cleaning or solar heating system and plenty of other function. 
For all these requirements we have developed universal control unit that is designed to be used as a control system for all these components, Fig 1.

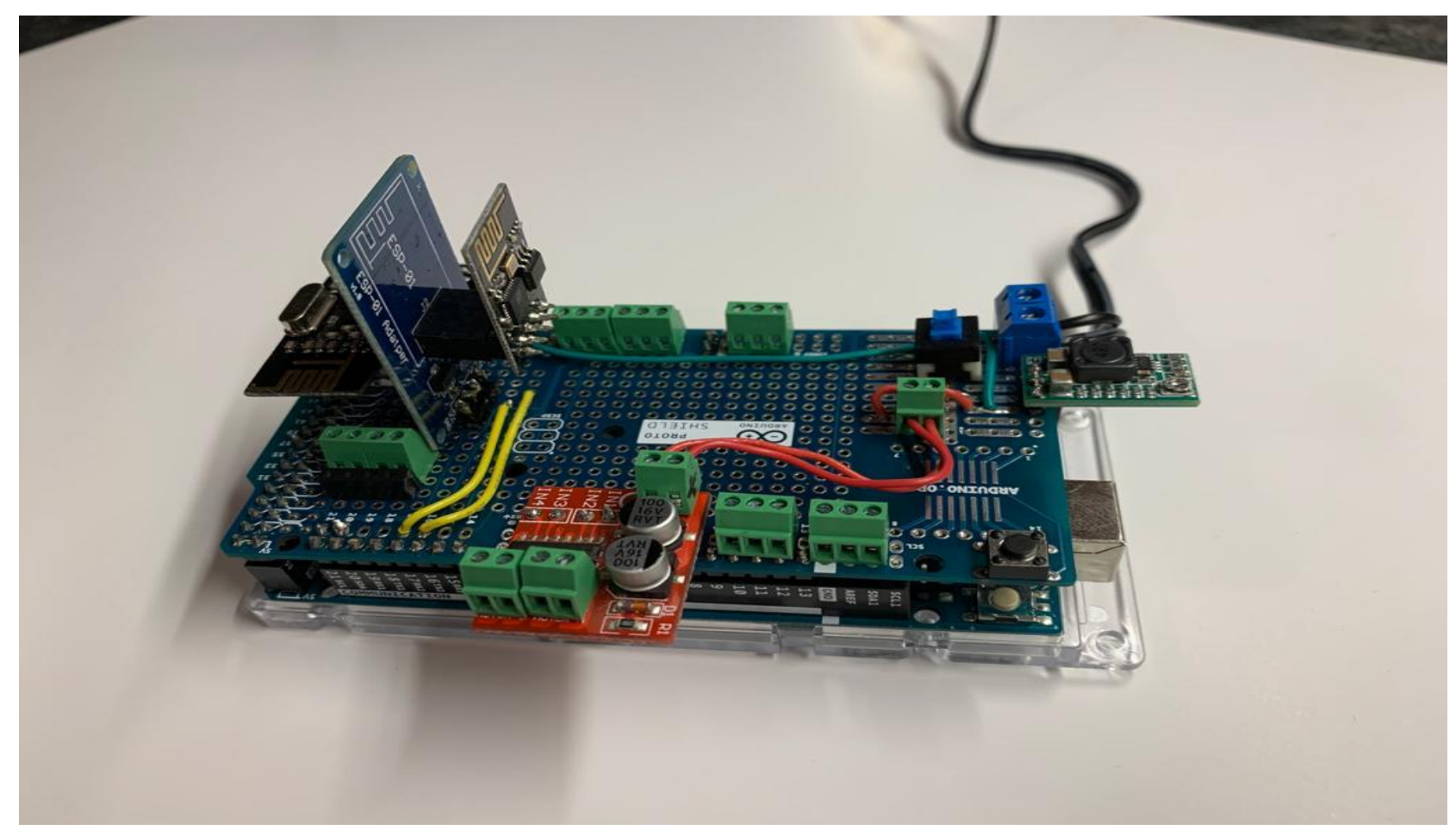

Fig. 1. The universal control unit

\section{The universal control unit}

The universal control unit has to meet the following requirements:

- $\quad$ the control unit is able to solve combination and sequential problems based on automata

- $\quad$ the unit offers using easily programmable analog and digital inputs and outputs

- $\quad$ the unit offers using easily programmable buses like serial bus or i2c bus

- $\quad$ the unit is able to communicate with other units

- $\quad$ the unit is able to communicate with internet webpage and mobile phone control application

Created control unit is based on Arduino board. We also created one prototype of the unit with microprocessor ST. This prototype is smaller and more professional. The unit consists of the Arduino Mega board with additional PCB. There are several terminal groups there. In this case four terminals are used for basic digital inputs and outputs. The type of pin is configurable by program. It is possible to connect some digital sensors here like switches or some sensors of various quantities with digital output which changes when the adjusted level is reached. It is possible to connect some digital actuators here too like LED diods, optocouplers, relays or transistors. Next terminals are used for power supply of the sensors or actuators. The board contains step up and down converter which is typically adjusted to 6V. Next the unit includes couple of H-bridges. The H-Bridge enables to simply control actuators like DC motors or proportional valves using PWM.

Next terminals are used for i2c bus. It is possible to connect i2c sensors here or we use this bus to connect own OLED display to monitoring the state and parameters of the unit. Next the unit has two wifi modules for communication. First module ESP8266 serves to communication to mobile phone application and the second module nRF24L01 communicates with other control units of the production system.

\section{Library of general functions for automata}

Created control units must be able to solve combination and sequential tasks based on automata. The program of microprocessor is processed line by line from the beginning to the end repeatedly in infinity loop. There are two ways how to program solved problem. We can use one loop only and we can test all conditions in each cycle. In this case the microprocessor is more occupied. Or we can program the problem like automaton, fig. 2. It splits the main loop to several loops that represent states of the system. Then only conditions important in each state are tested. 


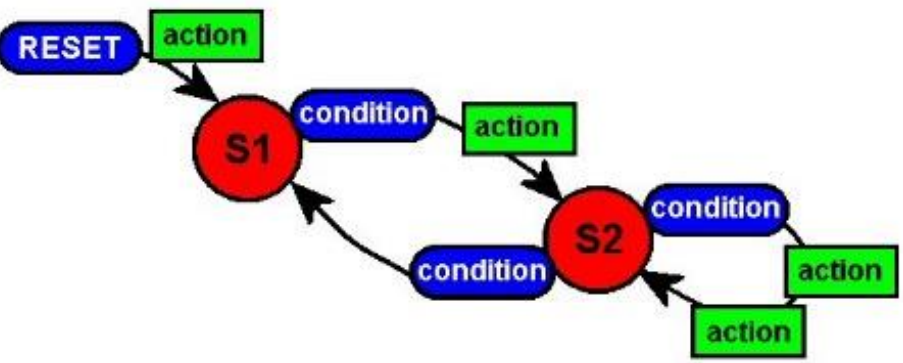

Fig. 2. Typical structure of an automaton.

The automaton consists of states, conditions with jumps and actions. There is the first part of automaton library in fig. 3 , states. There are blocks of states on the left side of the figure and corresponding programming code on the right side.

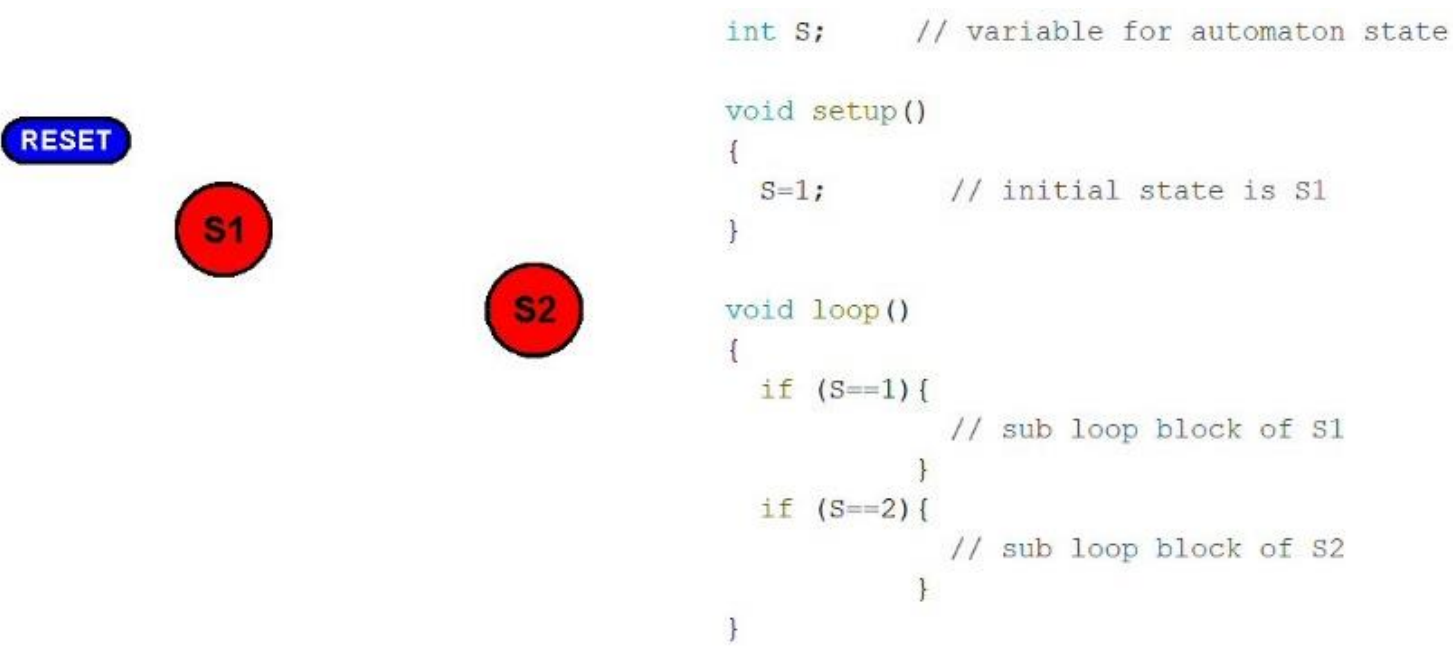

Fig. 3. The states of automaton

The second part of automaton is condition, fig.4. When the condition is fulfilled, the automaton jumps into next state. One or more conditions can be tested in each state. But all conditions are not tested in each cycle of program. It saves computing time and increases speed of interaction between the microprocessor and connected devices.

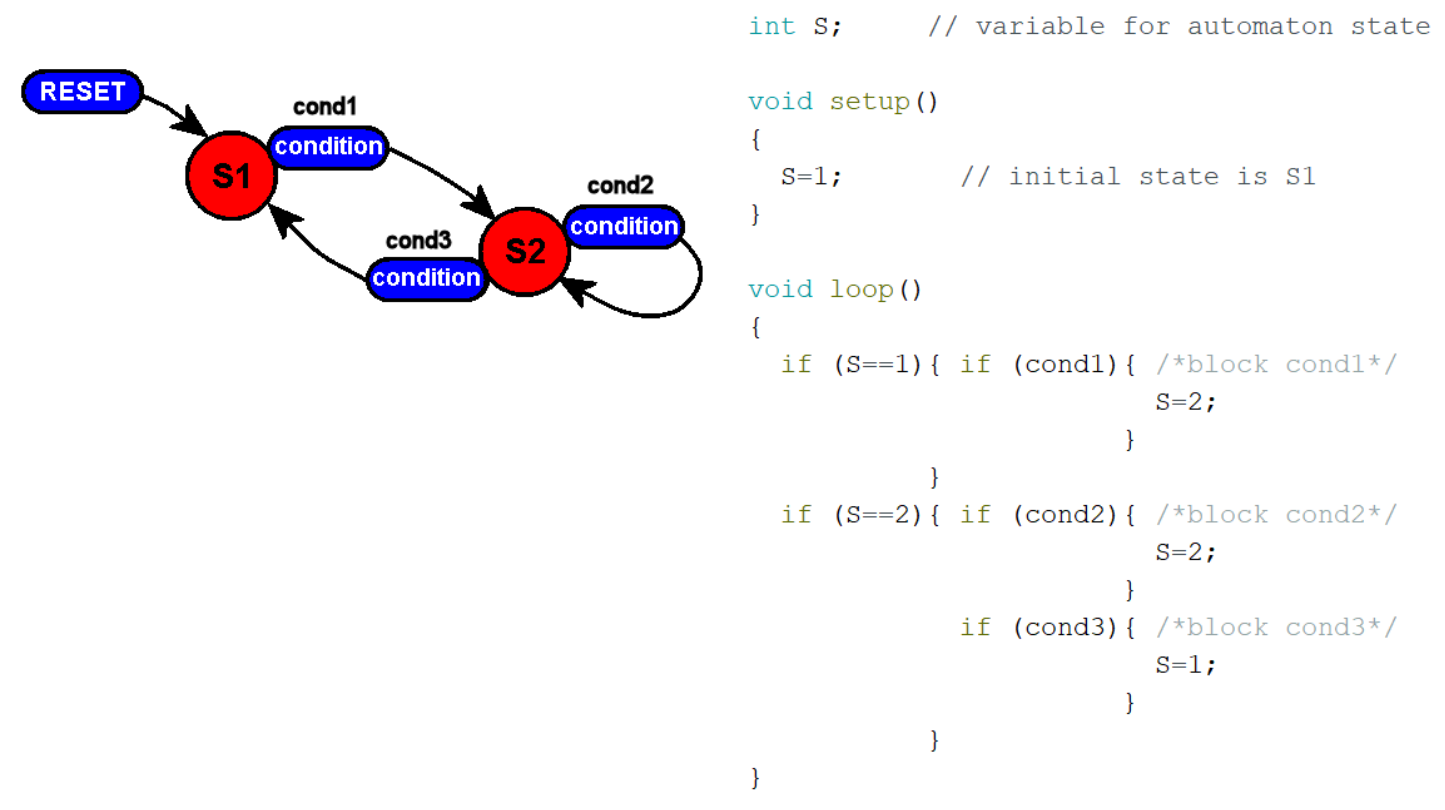

Fig. 4. The conditions and jumps of automaton 
The examples of conditions are in Fig.5. There is a description here:

a) the condition is fulfilled if some variable reaches adjusted value

b) the condition is fulfilled if the timer expires

c) the condition is fulfilled if the button is pressed

d) the condition is fulfilled if the button is released

e) the condition is fulfilled if analog sensor reaches adjusted value

f) the condition is fulfilled if digital sensor detects the change of its value

g) the condition is fulfilled if expected message is received

a)

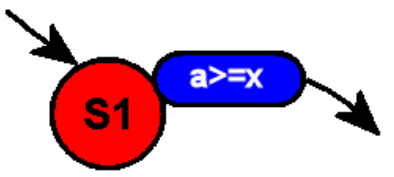

b)

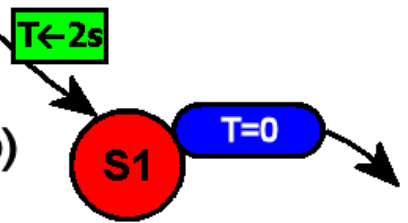

c)

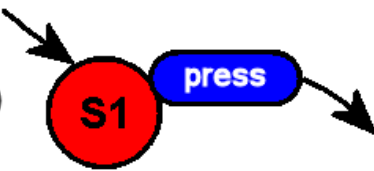

d)

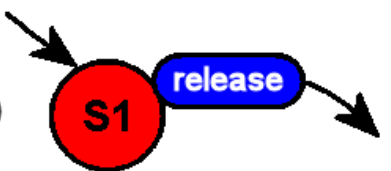

e)

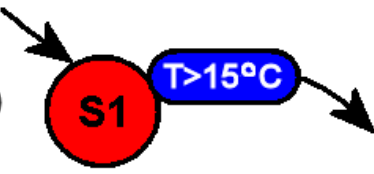

f)

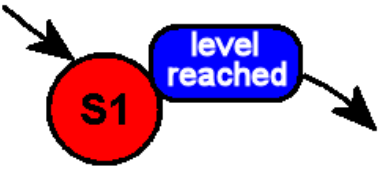

g)

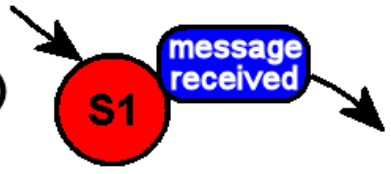

if $(a>=x) \quad\{/$ *actions*/ $\}$

stoptime=millis()+2000; //start of the timer before

if (millis () $>$ =stoptime) $\{/$ *actions*/ $\}$

buttonstate=! digitalRead (buttonPin);

if (buttonstate) \{/*actions*/ \}

buttonstate=! digitalRead (buttonPin) ;

if (!buttonstate) $\left\{/ /^{*}\right.$ actions*/ $\}$

sensorValue=analogRead (analogSensorPin) ;

if (sensorValue $>=$ a) \{/*actions*/ \}

sensorstate=! digitalRead(digitalsensorPin) ;

if (sensorstate $>=$ a) $\{/$ *actions*/ $\}$

while (myRadio.available())

\{myRadio.read (\&dataRecieve, sizeof (dataRecieve)) ;

if ( (dataRecieve.pwd==pwd) \&\& (dataRecieve.val==a))

$\{/ * a c t i o n s * /\}$

Fig. 5. The types of conditions

The last part of automatons are actions, fig. 6. The action is some command which is done during jump from one state to another state. The examples of conditions are in Fig.7.

There is a description here:

a) start of the timer

b) action which switches off some digital actuator (valve, LED diod, compressor, DC motor...)

c) action which switches on some digital actuator (valve, LED diod, compressor, DC motor...)

d) setting of analog actuators using PWM (brightness of LED, speed of DC motor, position of proportional valve...)

e) print some message to serial monitor and show some text on OLED lcd

f) send message throw wifi to another control unit 


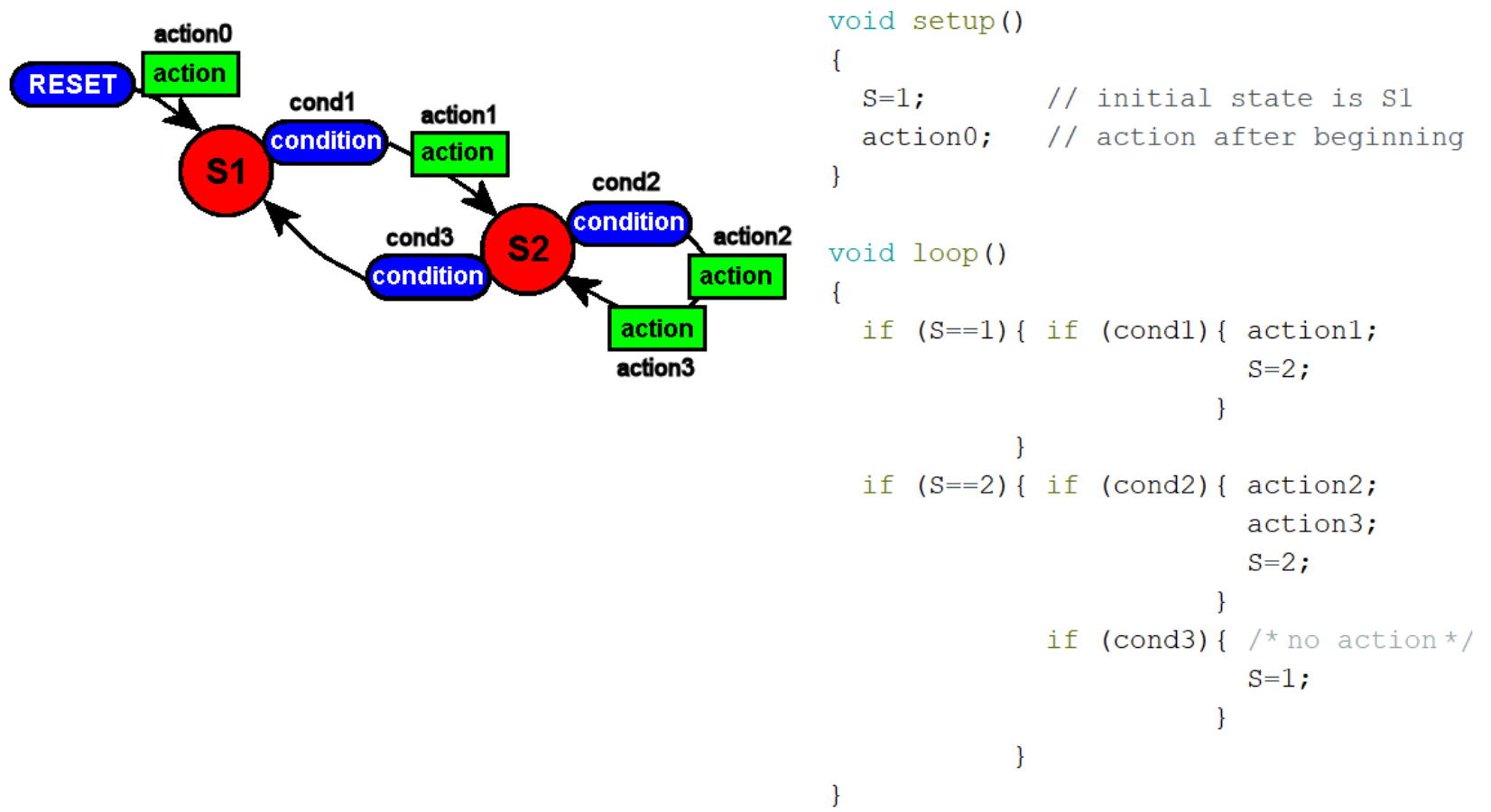

Fig. 6. The actions of automaton

a)

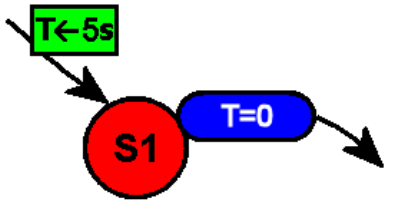

b)

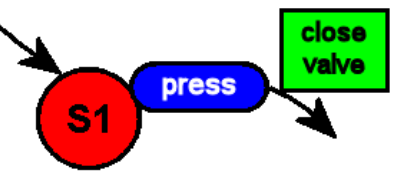

c)

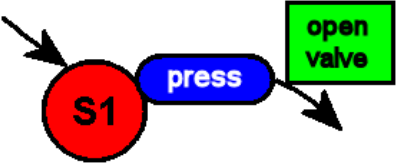

d)

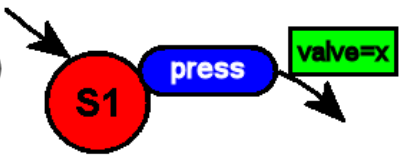

e)

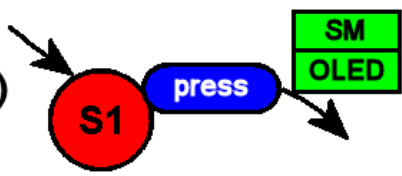

f)

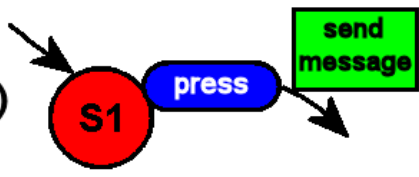

stoptime $=$ millis ( ) +5000 ;

digitalWrite (digitalActuatorPin, 0) ;

digitalWrite (digitalActuatorPin, 1) ;

analogWrite (analogActuatorPin, x) ;

println ("message") ;

myOled.setPrintPos $(0,12)$;

myoled.print("Control Unit") ;

myRadio.stopListening ( ) ;

dataTransmit. pwd=pwd;

dataTransmit. $\mathrm{val}=\mathrm{val}$;

myRadio.openWritingPipe (addresses [0]);

myRadio.write (\&dataTransmit, sizeof (dataTransmit)) ;

myRadio.openReadingPipe (1, addresses [0]) ;

myRadio.startListening ();

Fig. 7. The types of actions 


\section{Structure of messages for wifi communication}

The control units have to exchange some information and have to control flow of their automaton programs. The designed message consists of three parts. First part includes directional information like security information, count of transmitted and received messages and address of target control unit. Some parameters are optional. Second part includes predefined control codes and the last part consists of data. It is possible to transmit integer or float values, characters or strings and their arrays. The structure of the message is in fig. 8 . The principal of sending and receiving the messages was described in Fig. $5 \mathrm{~g}$ ) and in Fig. 7 f).

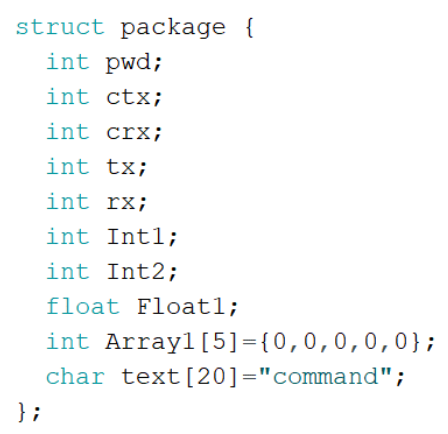

Fig. 8. Structure of wifi message

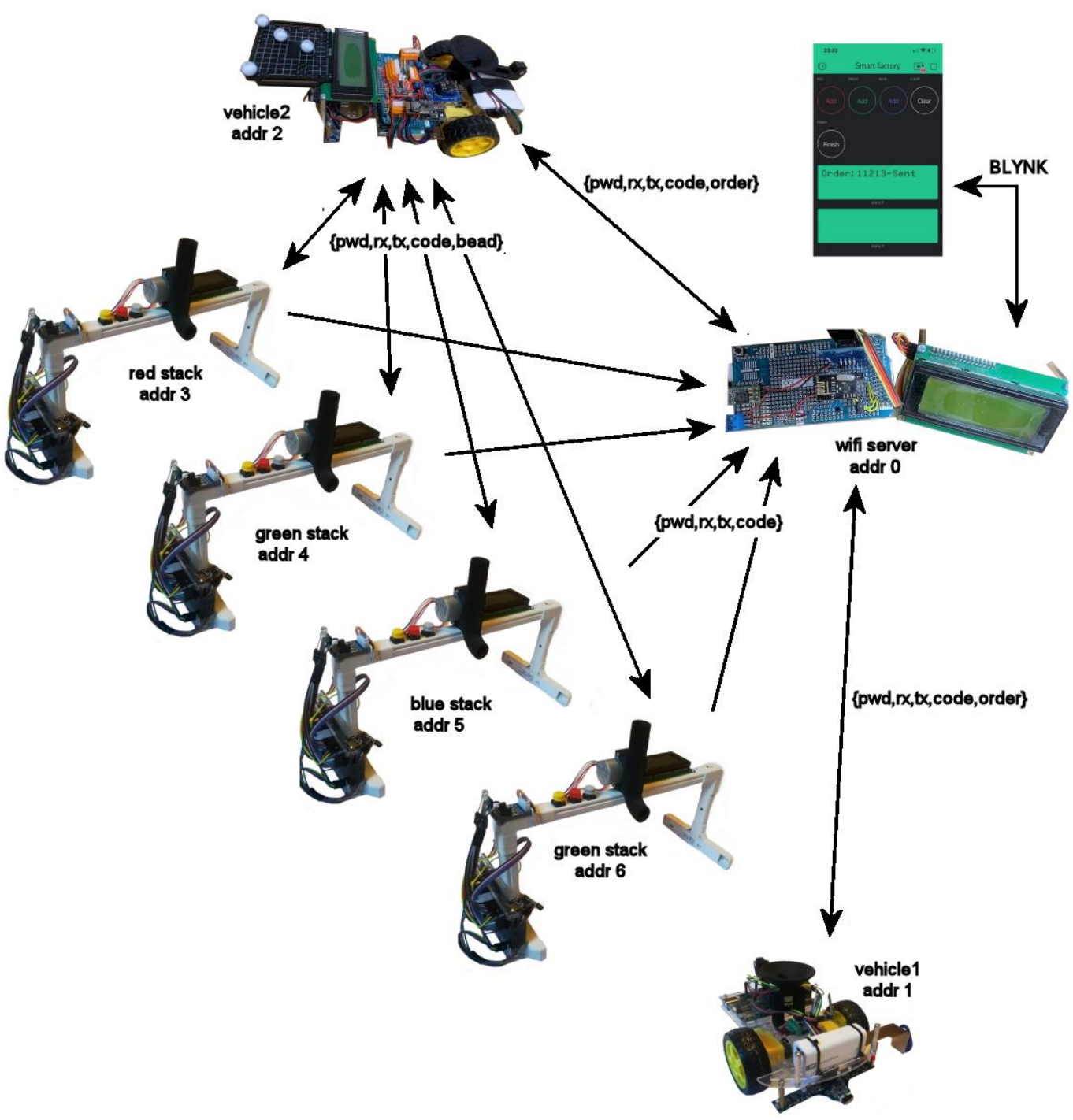

Fig. 9. Production system of bracelet 
The real content of the messages depends on controlled system. In case of production system of colourful bracelet, fig.9, the system of control codes was created. The system consists of the mobile phone wifi server with address 0 . This server obtains the order from mobile application and sends the order to the vehicles with addresses 1 and 2 . This message includes password, address rx of asked vehicle, address tx of the server and an array with the order. Next the vehicle has to go following the line path throw stacks with beads of various colour. Addresses of the stacks are 3 and higher. The messages between the vehicle and the stacks include password, address rx of asked stack, address tx of the vehicle and integer value of asked bead. The stack answers with predefined codes that depend on wrong or right colour. As soon as the entire order is completed, the vehicle leaves the paths and send the message to mobile application throw the server. Here are predefined integer codes used too.

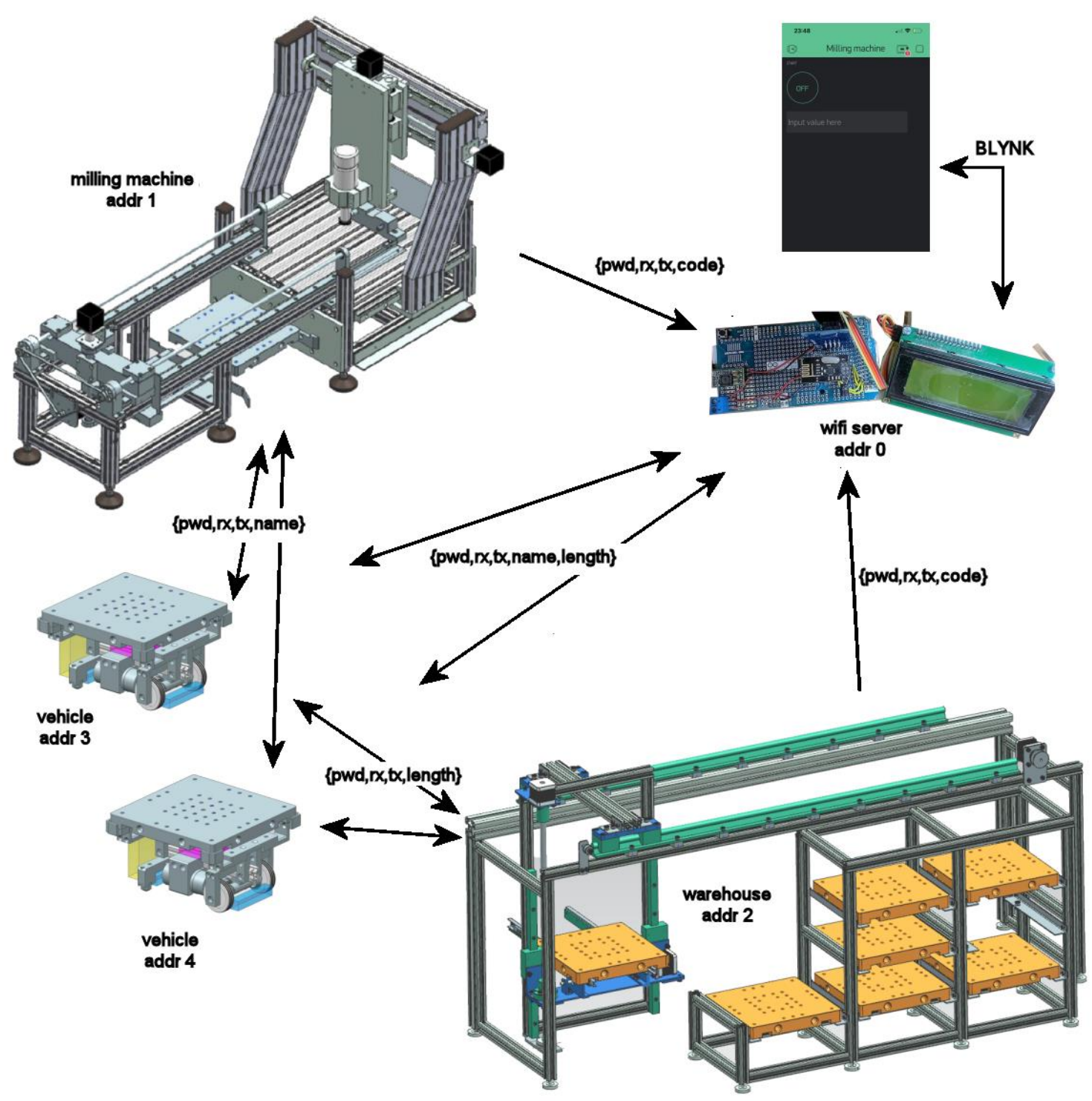

Fig. 10. Production system of the labels with name

Next system solves production of the little plate with name, fig. 10. The plate like business card or card with name to door. The customer writes a text on the phone application - the name and surname he wants to mill into the plate. If it is a short name, it will take a small plate, if it is long name, it will take a bigger plate. The vehicle obtains the order throw wifi server. The message includes the password, addresses of server and the data with the name and its length. The vehicle has to go to the warehouse and has to ask for the suitable plate. The size of desired plate depends on name length. The messages between the vehicle and the warehouse include password, addresses of vehicle and warehouse and predefined code for asking, obtaining and finishing the delivery and the name length as integer value. As soon as the vehicle gets the plate of correct size from the warehouse, it goes with it to the milling machine, where it passes it together with the text to be milled, then loads it again and the process is finished. 


\section{Conclusion}

This paper focused on the control unit based on Arduino board, especially on its programming. A library of general functions for automatons and structure of messages for wifi communication was designed. This control unit is suitable for small applications like to remotely glowing LED's, remote control of valves and another home automation. Several simple automatons were designed for the control units. It helps to write the program and to describe the states of control unit. Designed universal control unit was tested in two real production systems too. The first was a model of a smart factory with the production of a colored bracelet and the second system was the production system of the little plate with name. Created control unit is designed to be used as a control system for all components of these production systems, servers, vehicles, stacks, warehouse and milling machine is production system of the little plate with name. It consists of a plate warehouse, a vehicle and a milling machine. A new smaller version with ST microprocessor was designed too. We are going use created control unit to several home automation tasks. The security of data transportation is important [5]. We will have to increase the security using new private server with https connection and using encryption.

\section{Acknowledgments}

This publication was written at the Technical University of Liberec as part of the project "(21278) - Optimization of manufacturing systems, 3D technologies and automation“" with the support of the Specific University Research Grant, as provided by the Ministry of Education, Youth and Sports of the Czech Republic in the year 2019

\section{References}

[1] Votrubec, R \& Koblasa, F. (2019). Control System of Vehicle for Smart Factory Model with Principles of Industry 4.0, Proceedings of the 30th DAAAM International Symposium, pp.0261-0267, B. Katalinic (Ed.), Published by DAAAM International, ISBN 978-3-902734-22-8, ISSN 1726-9679, Vienna, Austria

[2] Sevic, M. (2017). Design of small CNC machine for the model of production system with principles Industry 4.0. Master Thesis, Department of production systems and automation, Technical University of Liberec, Liberec, Czech Republic.

[3] Koblasa, F.; Votrubec, R.; Lelek, L. \& Koudelka, J. (2019). Project oriented teaching in Industry 4.0 - smart home. Industry engineering 2019: International student scientific conference. Pilsen, Czech Republic. ISBN 9788026108948.

[4] Bartodziej, Ch. J., (2016), The concept industry 4.0. New York, NY: Springer Berlin Heidelberg, ISBN 978-3-658165017.

[5] Thanes, L. \& Schaefer, D. (2017). Cybersecurity for Industry 4.0: Analysis for Design and Manufacturing. Switzerland: Springer International Publishing, ISBN 978-3-319-50659-3.

[6] Takakuwa, S.; Veza, I. \& Celar, S. (2018). Industry 4.0 in Europe and East Asia, Proceedings of the 29th DAAAM International Symposium, B. Katalinic (Ed.), Published by DAAAM International, ISBN 978-3-902734-20-4, ISSN 1726-9679, Vienna, Austria.

[7] Palcic, I.; Ojstersek, R. \& Buchmeister, B. (2018). Creating Value in Manufacturing Companies, Proceedings of the 29th DAAAM International Symposium, B. Katalinic (Ed.), Published by DAAAM International, ISBN 978-3902734-20-4, ISSN 1726-9679, Vienna, Austria.

[8] Medojevic, M.; Diaz Villar, P.; Cosic, I.; Rikalovic A.; Sremcev, N. \& Lazarevic, M. (2018). Energy Management in Industry 4.0 Ecosystem: a Review on Possibilities and Concerns, Proceedings of the 29th DAAAM International Symposium, B. Katalinic (Ed.), Published by DAAAM International, ISBN 978-3-902734-20-4, ISSN 1726-9679, Vienna, Austria.

[9] Ojstersek, R.; Acko, B. \& Buchmeister, B. (2020). Simulation study of a flexible manufacturing system regarding sustainability, International Journal of Simulation Modelling, Vol. 19, No. 1, 65-76, doi:10.2507/IJSIMM19-1-502 